\title{
KELAYAKAN FINANSIAL BUDI DAYA SARANG BURUNG WALET DI KECAMATAN MALINAU BARAT KABUPATEN MALINAU
}

\section{FEASIBILITY FINANCIAL FOR SWALLOW'S NEST CULTIVATION IN SUB DISTRICT OF WEST MALINAU DISTRICT OF MALINAU}

\author{
Bili Caesar ${ }^{1^{*}}$, Bayu Nuswantara ${ }^{2}$ \\ ${ }^{1}$ Jurusan Agribisnis, Fakultas Pertanian dan Bisnis, Universitas Kristen Satya Wacana. \\ ${ }^{2}$ Staff Pengajar Program Studi Agribisnis, Fakultas Pertanian dan Bisnis, \\ Universitas Kristen Satya Wacana. Salatiga. \\ *E-mail corresponding: 522016009@student.uksw.edu
}

\begin{abstract}
ABSTRAK
Usaha penangkaran burung walet merupakan salah satu usaha yang mempunyai prospek cerah untuk dikembangkan di Indonesia pada saat ini. Hal tersebut didukung oleh kondisi lingkungan dan geografis yang sesuai serta sumber daya yang tersedia untuk mendukung kehidupan burung walet yang dapat ditemukan pada beberapa daerah tertentu di indonesia. Sarang burung walet merupakan usaha pilihan untuk menambah penghasilan dan menjadi usaha yang meningkatkan ekonomi masyarakat sekitar. Penelitian ini bertujuan untuk menganalisis kelayakan finansial usaha sarang burung walet di Kecamatan Malinau Barat Kabupaten Malinau Kalimantan Utara. Metode yang digunakan adalah survei. Lokasi penelitian dipilih secara sengaja yaitu di Kecamatan Malinau Barat dengan pertimbangan daerah ini merupakan salah satu Kecamatan yang memiliki letak geografis yang sesuai dengan kehidupan burung walet. Jumlah sampel yang digunakan adalah sebanyak 30 pembudidaya sarang burung walet. Penelitian ini menggunakan analisis kelayakan finansial dengan 6 kriteria yaitu R/C Ratio, Break Even Point (BEP), Net Present Value (NPV), Net Benefit Cost Ratio (Net B/C), Internal Rate Of Return (IRR) dan Analisis Data Secara Deskriptif. Hasil penelitian menunjukan discount Factor $8 \%$ menunjukan R/C Ratio sebesar 3.10 BEP sebesar Rp. 45.084.475,- NPV sebesar Rp. 627,738,439,- Net B/C sebesar 2.47 dan IRR sebesar $78.63 \%$. Berdasarkan kegiatan tersebut usaha sarang burung walet ini layak untuk diusahakan secara finansial.
\end{abstract}

Kata kunci: Budi Daya Sarang Burung Walet, Finansial Burung Walet.

\begin{abstract}
Swallow breeding business is one of the businesses that have bright prospects to be developed in Indonesia at this time. This is supported by suitable environmental and geographic conditions as well as the available resources to support swallow bird life which can be found in certain areas in Indonesia. Swallow's nest is an optional business to increase income and become a business that improves the economy of the surrounding community. This study aims to analyze the financial feasibility of a swallow's nest business in West Malinau District, Malinau Regency, North Kalimantan. The method used is a survey. The research location was chosen deliberately, namely in the West Malinau District with the consideration that this area is one of the Districts that has a geographical location that is suitable for the life of swallows. The number of samples used was 30 swallow's nest cultivators. This study uses financial feasibility analysis with 6 criteria, namely R / C Ratio, Break Even Point (BEP), Net Present Value (NPV), Net Benefit Cost Ratio (Net B / C), Internal Rate Of Return (IRR) and Data Analysis. Descriptively. The results showed the discount factor of $8 \%$ showed an $R / C$ ratio of 3.10 BEP of Rp. 45,084,475, - NPV of Rp.
\end{abstract}




\section{KELAYAKAN FINANSIAL BUDI DAYA SARANG BURUNG WALET DI KECAMATAN MALINAU \\ BARAT KABUPATEN MALINAU \\ Bili Caesar, Bayu Nuswantara}

$627,738,43,-$ Net B / C of 2.47 and an IRR of $78.63 \%$. Based on these activities, the swallow nest business is feasible to be financially operated.

Keywords: Swallow's Nest Cultivation, Swallow Finances

\section{PENDAHULUAN}

Prospek bisnis sarang burung walet dari tahun ketahun semakin meningkat. Hal ini terbukti dari jumlah ekspor ke negara-negara lain semakin bertambah, untuk meningkatkan ekspor yang lebih besar, diperlukan teknik-teknik pemeliharaandan perlakuan sarang yang lebih baik lagi, sehingga mampu meningkatkan kualitas maupun kuantitas hasil sarang burung walet, dan mampu memenuhi permintaan pasar baik dalam maupun luar negri. (Dewi, 2011). Usaha penangkaran burung walet membutuhkan investasi yang cukup besar, maka sejak awal dibutuhkan perencanaan yang matang dan pengetahuan yang utuh mengenai faktor-faktor yang terdapat dalam pengembangan usaha penangkaran burung walet. Hal ini sangat diperlukan untuk menekan risiko dan ketidakpastian sekecil-kecilnya, sehingga diperoleh optimalisasi sumberdaya yang digunakan. Dalam usahanya para penangkar menghadapi beberapa kendala diantaranya dalam hal penentuan harga, karena keterbatasan para penangkar terhadap informasi pasar dan burung walet merupakan satwa liar sehingga menyebabkan pendapatan para penangkar tidak menetap. (Nugroho dan Budiman, 2009)
Untuk memulai usaha budidaya walet, ada beberapa faktor yang sangat penting untuk budidaya sarang burung walet, yaitu: "lokasi, iklim, kondisi lingkungan, bentuk bangunan, faktor makanan serta teknik memancing walet". Semua faktor ini sangat penting untuk keberhasilan budidaya sarang burung walet. Di samping itu, gedung burung walet harus seperti gua liar karena itulah habitat asli burung walet. (Nugroho dan Budiman, 2009).

Tujuan penelitian ini adalah untuk Mengetahui tingkat kelayakan finansial usaha budi daya sarang burung walet di Kecamatan Malinau Barat Kabupaten Malinau.

\section{METODE PENELITIAN}

Lokasi penelitian terambil dari Kecamatan Malinau Barat Kabupaten Malinau. Pemilihan lokasi dilakukan secara sengaja (purposive). Adapun pertimbangan memilih kecamatan malinau barat sebagai tempat penelitian karena kecamatan malinau barat menampung banyak warga yang hampir setiap sudutnya memiliki gedung/rumah walet.

Jenis penelitian ini adalah penelitian deksriptif kuantitatif, yaitu suatu metode yang tidak hanya memberikan gambaran mengenai fenomena, tetapi juga 
menerangkan pengaruh, menguji hipotesis, membuat prediksi serta mendapatkan makna dan implikasi dari suatu masalah yang ingin dipecahkan (Nazir, 1988).

Teknik pengambilan sampel yang digunakan pada penelitian ini menggunakan teknik purposive sampling dengan pendekatan non probability sampling. Metode ini menggunakan kriteria yang telah dipilih oleh peneliti dalam memilih sampel. Kriteria pemilihan sampel terbagi menjadi kriteria inklusi dan eksklusi.

Dalam penelitian ini, analisis data menggunakan R/C ratio, Break Event Point (BEP), Net Persent Value (NPV), Net Benefit Cost Ratio (Net B/C), Internal Rate Return (IRR).

\section{HASIL DAN PEMBAHASAN \\ Biaya Usaha Budi Daya Sarang Burung Walet}

Tabel 1. Biaya Total Budi Daya Sarang Burung Walet di Kecamatan Malinau Barat

\begin{tabular}{|c|c|c|c|}
\hline Uraian & Jumlah Fisik & Harga/Satuan & Nilai (Rp) \\
\hline \multicolumn{4}{|l|}{ Biaya Tunai } \\
\hline 1. Parfume Organik & 6 & 100.000 & 616.666 \\
\hline 2. Pestisida Cyperkiller & 30 & 2.000 & 60.000 \\
\hline 3. Tenaga Kerja HOK & 1 & 40.000 & 156.400 \\
\hline Total Biaya Variabel & & & 843.333 \\
\hline \multicolumn{4}{|l|}{ Biaya Tetap } \\
\hline 1. Alat & & & 3.600 .833 \\
\hline Kabel & 82 & 2.000 & 164.000 \\
\hline Tweeter & 52 & 25.000 & 1.300 .000 \\
\hline Amply & 1 & 800.000 & 800.000 \\
\hline Accu & 1 & 800.000 & 800.000 \\
\hline Semprotan & 1 & 500.000 & 500.000 \\
\hline Kuas & 0,66 & 25.000 & 15.500 \\
\hline Ember & 0,66 & 10.000 & 6.600 \\
\hline 2. Biaya Bangunan & & & 33.650 .000 \\
\hline Bangunan & 136 & 32.266 .667 & \\
\hline Instalasi & 136 & 1.383 .333 & \\
\hline 3. Nilai Penyusutan & & & 5.960 .133 \\
\hline Bangunan \& Instalasi & & & 5.384 .000 \\
\hline Alat & & & 576.133 \\
\hline Total Biaya Tetap & & & 43.210 .966 \\
\hline $\mathrm{TC}$ & & & 44.054 .300 \\
\hline
\end{tabular}

Sumber: Data Primer diolah,2020

Biaya Tetap Yang di perhitungkan adalah Penyusutan, alat dan Bangunan. Biaya Penyusutan Berupa Alat dan Bangunan. Penyusutan alat dan bangunan di perkirakan selama 5 tahun ke depan.

Biaya keseluruhan untuk 1 gedung rumah walet di Kecamatan Malinau Barat adalah sebesar Rp. 44.054.300,- untuk luas lahan $136 \mathrm{~m}^{2}$. 


\section{Analisis Pendapatan}

Berdasarkan biaya usaha dan penerimaan usaha Pendapatan yang diterima pada usaha Budi daya sarang burung walet di Kecamatan Malinau Barat rata-rata sebesar Rp. 9.594.285,-. Tabel berikut adalah tabel rata-rata biaya, penerimaan dan pendapatan.

Tabel 2. Rata-rata Biaya, Penerimaan dan Pendapatan Per Tahun

\begin{tabular}{clr}
\hline No & \multicolumn{1}{c}{ Uraian } & Rata-rata (Rp/Tahun) \\
\hline 1 & Biaya & 44.054 .300 \\
2 & Penerimaan & 111.593 .600 \\
3 & Pendapatan & 67.539 .300 \\
\hline
\end{tabular}

Sumber: Data Primer diolah, 2020.

\section{Analisis Kelayakan Usaha Budi Daya Sarang Burung Walet}

Tabel 3. Penerimaan dan Kelayakan Usaha Budid Daya Sarang Burung Walet di Kecamatan Malinau Barat

\begin{tabular}{lcrr}
\hline Keterangan & Harga/Satuan & Jumlah Fisik & Nilai (Rp) \\
\hline Penerimaan Usaha Budi Daya & & & \\
\hline Penerimaan Tunai (1 Tahun) & & & 111.593 .600 \\
1. Mangkok & 120.000 & 0,33 & 3.960 .000 \\
2. Sudut & 80.000 & 0,33 & 2.640 .000 \\
\hline Biaya Usaha Budi Daya & & & 44.054 .300 \\
\hline Pendapatan atas Biaya Total & & 67.539 .300 \\
\hline R/C Ratio Biaya Total & & 3,10 \\
\hline Total Produksi & & 0,66 \\
\hline Harga Jual & & 200.000 \\
\hline BEP Volume Produksi & & 20.000 .00 \\
\hline BEP Harga Produksi & & 45.084 .475 \\
\hline
\end{tabular}

Sumber: Data Primer diolah, 2020

Dari hasil analisis yang dilakukan kepada 30 responden didapatkan ratarata $\mathrm{R} / \mathrm{C}$ Ratio sebesar 3,10. Dilihat dari perbandingan antara penerimaan dan biaya R/C Ratio adalah 3,10. Nilai 3,10 ini berarti setiap biaya yang dikeluarkan responden sebesar Rp. 1,- responden akan menerima penerimaan sebesar Rp. 3,10, dari R/C Ratio ini didapat kesimpulan bahwa usaha budi daya sarang burung walet di Kecamatan
Malinau Barat layak untuk diusahakan, karena penerimaan lebih besar dari biaya yang di keluarkan R/C Rasio $>1$.

Dari hasil analisis yang dilakukan kepada 30 responden didapatkan ratarata BEP harga sebesar Rp. 45.084.475,ini berarti harga BEP lebih besar dari harga rata-rata yaitu Rp. 20.000.000,-, sehingga usaha layak untuk diusahakan.

Analisis Finansial Net Present Value (NPV) 
Tabel 4. Perhitungan Net Present Value (NPV) (Dalam Rupiah)

\begin{tabular}{rllrrr}
\hline Year & Cash In & Cash Out & Net Cash Flow & DF 8\% & NPV \\
\hline 0 & $44,054,300$ & $44,054,300$ & 0 & 1 & 0 \\
1 & $111,593,600$ & $10,438,033$ & $101,155,567$ & 0.93 & $93,662,562$ \\
2 & $164,484,000$ & $10,481,887$ & $154,002,113$ & 0.86 & $132,031,990$ \\
3 & $228,900,000$ & $10,537,142$ & $218,362,858$ & 0.79 & $173,343,477$ \\
4 & $184,536,000$ & $10,605,474$ & $173,930,526$ & 0.74 & $127,844,129$ \\
5 & $158,880,000$ & $10,689,035$ & $148,190,965$ & 0.68 & $100,856,281$ \\
\hline NPV & & & & $627,738,439$ \\
\hline
\end{tabular}

Sumber: Data Primer diolah,2020

Berdasarkan hasil analisis pada dari nol tersebut maka usaha dikatakan usaha sarang burung walet menunjukan layak untuk diusahakan.

NPV bernilai positif yaitu sebesar

Analisis Net Benefit/Cost Ratio (Net Rp. $627,738,439,-$ pada tingkat suku $B / C)$ bunga $8 \%$ dari hasil NPV yang lebih besar

Tabel 5. Perhitungan Net Benefit/Cost Ratio (+)

\begin{tabular}{cccc}
\hline Year & Net Benefit & DF 8\% & PV \\
\hline 0 & 0 & 1 & 0 \\
1 & $101,155,567$ & 0.93 & $93,662,562$ \\
2 & $154,002,113$ & 0.86 & $132,031,990$ \\
3 & $218,362,858$ & 0.79 & $173,343,477$ \\
4 & $173,930,526$ & 0.74 & $127,844,129$ \\
5 & $148,190,965$ & 0.68 & $100,856,281$ \\
\hline NPV + & & $627,738,439$ \\
\hline
\end{tabular}

Sumber: Data Primer diolah, 2020

Tabel 6. Perhitungan Net Benefit/Cost Ratio (-)

\begin{tabular}{cccc}
\hline Year & Net Benefit & DF $50 \%$ & PV \\
\hline 0 & 0 & 1 & 0 \\
1 & $101,155,567$ & 0.67 & $67,437,044$ \\
2 & $154,002,113$ & 0.44 & $68,445,384$ \\
3 & $218,362,858$ & 0.30 & $64,700,106$ \\
4 & $173,930,526$ & 0.20 & $34,356,647$ \\
5 & $148,190,965$ & 0.13 & $19,514,860$ \\
\hline NPV - & & & $254,454,041$ \\
\hline
\end{tabular}

Sumber: Data Primer diolah, 2020

Net $B / C=627,738,439 / 254,454,041$

Net $B / C=2.47$ 


\section{KELAYAKAN FINANSIAL BUDI DAYA SARANG BURUNG WALET DI KECAMATAN MALINAU \\ BARAT KABUPATEN MALINAU \\ Bili Caesar, Bayu Nuswantara}

Hasil dari analisis Net B/C Ratio usaha sarang burung walet pada faktor diskon $8 \%$ adalah sebesar 2,70. Setiap pengeluaran sekarang sebesar Rp. 1 akan memberikan manfaat (benefit) sebesar Rp. 2,70 kali lipat dari biaya yang dikeluarkan. Dari nilai tersebut diketahui bahwa Net B/C Ratio dari 1 maka usaha sarang burung walet menguntungkan serta layak untuk diusahakan.

Analisis Internal Rate Of Return (IRR)

Tabel 7. Perhitungan Internal Rate Return (IRR)

\begin{tabular}{cccc}
\hline Year & Net Cash Flow & $8 \%$ & $50 \%$ \\
\hline 0 & 0 & 0 & 0 \\
1 & $101,155,567$ & $93,662,562$ & $67,437,044$ \\
2 & $154,002,113$ & $132,031,990$ & $68,445,384$ \\
3 & $218,362,858$ & $173,343,477$ & $64,700,106$ \\
4 & $173,930,526$ & $127,844,129$ & $34,356,647$ \\
5 & $148,190,965$ & $100,856,281$ & $19,514,860$ \\
\hline Total & & $627,738,439$ & $254,454,041$ \\
\hline IRR & & & $78.63 \%$ \\
\hline
\end{tabular}

Sumber: Data Primer diolah, 2020

Berdasarkan hasil analisis pada usaha sarang burung walet diperoleh hasil perhitungan IRR sebesar $78.63 \%$ \%. Ini berarti menunjukkan bahwa "Returns to Capital Investased" (pengembalian modal investasi) selama 5 periode pengusahaan sarang burung walet layak untuk diusahakan. Karena IRR yang dihasilkan lebih besar dari bunga bank yang berlaku.

\section{KESIMPULAN}

Berdasarkan hasil penelitian dan pembahasan dapat disimpulkan :

Analisis kelayakan finansial yang dilakukan menghasilkan nilai yang memenuhi syarat kelayakan untuk kelangsungan suatu proyek. Hal ini dapat dibuktikan dengan nilai R/C Ratio yang didapat yaitu sebesar 3.10 yang artinya layak. Dan harga BEP sebesar Rp. 45.084.475,- ini berarti harga BEP lebih besar dari harga rata-rata yaitu $\mathrm{Rp}$. 20.000.000,-, sehingga usaha layak untuk diusahakan. NPV yang didapat yaitu sebesar Rp. 627,738,439,- pada tingkat suku bunga sebesar $8 \%$ untuk periode 5 tahun. Sedangkan Net B/C yang didapat sebesar 2.47, nilai IRR sebesar $78.63 \%$ dan payback periode yaitu 1 tahun. Dengan melihat kelima nilai hasil analisis kelayakan finansial R/C Ratio lebih dari 1, harga BEP lebih besar dari harga ratarata, NPV yang positif, nilai Net B/C Ratio lebih besar dari satu, dan nilai IRR yang lebih besar dari discount factor. Dapat dikatakan bahwa usaha sarang burung walet di Kecamatan Malinau Barat untuk 5 tahun kedepan adalah layak untuk dikembangkan. 


\section{DAFTAR PUSTAKA}

Nazaruddin \& A. Widodo. Sukses Merumahkan Walet. Cet. 2 Jakarta: Penebar Swadaya, 1998

Dr. Lim Chan Koon (2002), Swiftlets of Borneo. Lee Ngan Woon (1999), Bird Nest Recipes

Arif Budiman, Memanggil @Mengasuh Walet dengan Sriti Kembang (edisi Revisi), Depok: AgroMedia Pustaka. PT

Mackinnon, Jhon. Panduan Lapangan Pengenalan Burung-burung di Jawa dan Bali. Yogyakarta: Gadjah Mada University Press, 1994.

Salekat, Nasir, 2009. Membangun Rumah Walet Hemat Biaya. Agromedia Pustaka. Jakarta.

Mardiastuti, A., Y.A. Mulyani., J. Sugarjito., L.N. Ginoga., I. Maryanto., A. Nugraha., Ismail. 1998. Teknik Pengusahaan Walet Rumah, Pemanenan Sarang dan Penaganan Pasca Panen. Dewan Riset Nasional. Jakarta.

Nazir,Moh. 2005. Metode Penelitian. Cetakan Keenam. Penerbit Ghalia. Indonesia.

Dewi, Siska. 2011. Bisnis Jitu Budi Daya Walet. Jl. Jogja-Solo Km. 11.5. Purwomartani Kalasan Sleman Yogyakarta.

Budiman, Arief. 2019. 101 Kiat Mengatasi Permasalahan Budi Daya Walet. JI. $\mathrm{H}$. Montong No.57, Ciganjur, Jagakarsa Jakarta Selatan 12630: Redaksi AgroMedia Pustaka.

Tim Penulis PS. Budidaya dan Bisnis Sarang Walet. Cet. 4. Jakarta: Penebar Sawadaya, 1994. 